\title{
ECOPERSONALISMO E DIREITO AO MEIO AMBIENTE*
}

\author{
Jesús Ballesteros**
}

O objetivo do presente artigo consiste em refletir brevemente sobre as conseqüências, no âmbito do direito ao meio ambiente, das diferentes concepções sobre a relação entre o ser humano e a natureza, isto é, o modelo tecnocrático, o biologista e o ecológico-personalista ${ }^{1}$.

\section{A) MODELO TECNOCRÁTICO}

O modelo tecnocrático crê na disponibilidade ilimitada da natureza, reduzida a um simples recurso ao serviço da propriedade privada e da criação de mercadorias segundo a visão do ser humano como homo faber. No pensamento economicista, os direitos são defendidos como se tratando de direitos de propriedade, isso a partir da afirmação de Locke que vê a personalidade como formando parte da propriedade. É a visão recolhida no Código Civil francês, por influência de Portalis, ao destacar o caráter exclusivo da propriedade e da sua disponibilidade ilimitada ${ }^{2}$. Uma panorâmica semelhante apresenta o discurso de Kant e Hegel inspirado no cartesianismo, na crença de que apenas a vontade possui direitos (Metaphysik der Sitten; Rechtsphilosophie, § 45). Isso lhes impedia de prever a necessidade de limites à disponibilidade no que se refere ao conjunto da natureza, a qual se via reduzida a puro objeto suscetível de apropriação exclusiva e ilimitada.

A mentalidade tecnocrática no âmbito jurídico leva à primazia dos bens exclusivos e disponíveis, de acordo com a crematística. Propõe-se, assim, a conversão de todo o âmbito da natureza em "coisa" suscetível de titularidade jurídica privada (property right) para sua

\footnotetext{
*Versão em português do texto "Ecopersonalismo y derecho al medio ambiente", publicado em Humana Iura: suplemento de derechos humanos, ISSN 1132-7294, n. 6, 1996 (Ejemplar dedicado a: El derecho humano al medio ambiente), pp. 15-36. Tradução de Albenir Itaboraí Querubini Gonçalves, revisão da tradução por Alfredo de J. Flores.

** Catedrático de Filosofia do Direito, Universidade de Valência (Espanha).

${ }^{1}$ Sobre o assunto, remeto ao meu livro BALLESTEROS. Ecologismo personalista: cuidar la natureza, cuidar al hombre. Madrid: Tecnos, 1995; e ao livro de V. BELLVER. Ecología: de las razones a los derechos. Granada: Comares, 1994; assim como a discussão sobre o modelo ecopersonalista, em Anuario de Filosofía del derecho, 1995, p. 651e ss.

${ }^{2}$ OST. La nature hors la loi. Paris: La Decouverte, 1995, p. 55 e ss.
}

(C) 2008. Departamento de Direito da UFSM. Todos os direitos reservados. 
melhor exploração, já que a finalidade dos recursos é que se convertam em mercadorias ${ }^{3}$. De acordo com esse sentido da propriedade resulta impossível limitar o consumismo e o esbanjamento. Ao faltar o sentido de transcendência, a cultura deixa de assentar-se no reconhecimento da igualdade econômica e se converte em frenética luta pelo enriquecimento, o que contribui para colocar em perigo o equilíbrio ecológico ${ }^{4}$. A proposta liberal de ver a personalidade como disponibilidade ilimitada dos recursos foi criticada, já em 1992, por Roscoe Pound (An introduction to the philosophy of law, The Yale University Press) ao afirmar que somente era defensável sem riscos enquanto houvesse abundância de recursos, porém não em um período de escassez, já que contribuiria para a ruína ecológica. De modo semelhante a Pound, Commons (Legal foundations of capitalism, New York, Macmillan, 1924) condena a carência de sentido de limites do liberalismo com relação aos bens naturais e sua exaltação do ius disponendi de re sua, e, por conseguinte, sua carência de sensibilidade ecológica.

Posteriormente, vem-se cobrando consciência de que esse modelo de propriedade conduz a um tipo de democracia baseada na defesa dos interesses dos que podem expressar suas preferências, pelo que resulta, portanto, claramente incompatível com a defesa duradoura do meio ambiente ${ }^{5}$.

Ao mesmo tempo, a superação do voluntarismo e a consciência do limite no exercício dos direitos devem servir para defender os direitos dos mais carentes de vontade e, mais concretamente, para proteger os direitos das futuras gerações.

\section{B) MODELO BIOLOGISTA}

A concepção biologista própria da Deep ecology e de todas as atitudes que priorizam a espécie sobre os indivíduos se baseia na superioridade do ecossistema como um todo (holismo) frente aos direitos da pessoa (considerada como parte), devido ao valor intrínseco de todo ser vivo. No fundo, pode ser vista como uma reedição da tese de Ulpiano sobre o direito natural, porém não se estendendo apenas aos animais, mas chegando até nos minerais.

\footnotetext{
${ }^{3}$ LEPAGE. Mañana el capitalismo. Madrid: Alianza, 1988.

${ }^{4}$ BECKER, E. La lucha contra el mal. México: FCE, 1975, p. 145 e ss.

5 A respeito desta temática: SCHUMPETER. Capitalismo, socialismo, democracia. México: Aguilar, 1952; MACPHERSON. La democracia liberal y su época. Madrid: Alianza Editorial, 1982; BALLESTEROS. Postmodernidad: decadencia o resistencia. Madrid: Tecnos, 1989, p. 76; OVEJERO. Democracia y ética ecologica. In: El papel de los consumidores en la protección ambiental. Valencia: Oficina Verde, Politécnica - CAM, 1996, p. 89 e ss.
}

(C) 2008. Departamento de Direito da UFSM. Todos os direitos reservados. 
Tal posição estabelece um igualitarismo entre espécies que é incompatível com a declaração de direitos unicamente para o ser humano: conduz, por sua vez, à proibição do atuar humano na biosfera, negando a licitude da administração da natureza, como forma de evitar a deterioração das outras espécies. Assim, a natureza não poderia ser entendida como simples recurso, já que seria o único e verdadeiro sujeito. Seria uma variante dessa tese a postura de Lovelock, na Hipótese Gaia, já que admite aspectos procedentes da mentalidade tecnocrática ${ }^{6}$.

\section{C) MODELO ECOPERSONALISTA}

\section{a) O sujeito dos direitos}

Todos os textos jurídicos internacionais e nacionais se opõem ao biologismo, enquanto consideram que o único sujeito do direito ao meio ambiente é o ser humano: todos os seres humanos atuais e potenciais, ou seja, as futuras gerações, mas não a natureza e os seres nãohumanos. Assim, a declaração de Estocolmo de 1972 estabelece que "o homem tem o direito fundamental a desfrutar de condições de vida adequadas em um meio de qualidade tal que lhe permita levar uma vida digna". De sua parte, a declaração do Rio de 1992 refere que "os seres humanos têm direito a uma vida saudável e produtiva, em harmonia com a natureza”. Por isso, sujeitos são todos os seres humanos, contrariando assim a Deep ecology e o utilitarismo, de uma parte (porque é apenas para seres humanos, o que estes não reconhecem), bem como os neomalthusianismos, de outra parte (porque é para todos os seres humanos, no que estes discordam).

A antropologia explícita na declaração de Estocolmo declara que "o homem é, ao mesmo tempo, obra e artífice do meio ambiente, o qual he dá o sustento material e lhe oferece a oportunidade de desenvolver-se intelectual, moral, social e espiritualmente"; porém, ao mesmo tempo, "graças à ciência e a tecnologia, o homem tem adquirido o poder de transformar, de inumeráveis maneiras e em uma escala sem precedentes, tudo que o cerca". Somente o ser humano é pessoa, portador de direitos e deveres. É necessário, portanto, manter propostas de caráter antropocêntrico, de acordo com a tradição dos direitos humanos e a

\footnotetext{
${ }^{6}$ No que tange à crítica ao "eco-reducionismo", entre outros: MORIN. EI método II. La vida de la vida. Madrid: Cátedra, p. 114; LOMBARDI. Il meritevole di tutela. Milano: Giuffrè, 1990, p. XCIV; OST. La nature hors la loi. Op. cit., p. 92.
}

(C) 2008. Departamento de Direito da UFSM. Todos os direitos reservados. 
filosofia personalista. Entretanto, esse antropocentrismo tem em conta a interdependência humana quanto ao seu entorno. Ser pessoa significa ser existente; por conseguinte, é um ser necessitado quanto ao conjunto da realidade: Deus, a natureza, os outros seres humanos. E, ao mesmo tempo, ser excelente, por sua capacidade de cuidado. Essa mesma mensagem personalista é a que aparece contida no art. 45 da Constituição Espanhola de 1978, ao referirse ao direito ao meio ambiente para o desenvolvimento da pessoa.

O sujeito específico, cuja proteção põe em primeiro lugar o direito ambiental, são as futuras gerações. Desde o final dos anos 60, surge a consciência da responsabilidade por ações presentes que possuem efeitos irreversíveis para o futuro ${ }^{7}$, como o efeito estufa, os resíduos nucleares, etc.

Sobre os direitos das futuras gerações, existem dois modelos que tem gozado de ampla difusão, mas que se mostram insuficientes:

a) O de John Rawls ${ }^{8}$, em sua Teoria da Justiça, publicada em 1971, um ano antes da Conferência de Estocolmo, ao limitar às gerações imediatas, até seus netos, a responsabilidade sincrônica, na linha do puro poupar bens econômicos, estabelecendo para os mais afastados uma responsabilidade decrescente. Seu modelo foi objeto de críticas por parte de B. Barry, como também, desde outra perspectiva, de V. Possenti ${ }^{9}$.

b) $\mathrm{O}$ do neomalthusiano Garret Hardin ${ }^{10}$, que afirma: "A conservação da vida em um país pobre, a cada ano, diminui a qualidade de vida das futuras gerações". Frente a isso, convém recordar que não se pode cogitar a respeito do problema das futuras gerações no sentido que pretende o Norte, ou seja, sem resolver previamente as condições de vida digna dos países do Sul.

É necessário assim que seja assegurada, para o futuro, a igualdade de oportunidades do presente. Por isso, é exigível a redução da produção e do consumo insustentável. Decorre dessa idéia a Declaração da UNESCO de 1994 de manter condições de vida semelhantes às presentes para o futuro. Desde 1985, existe em Malta um centro destinado à defesa de direitos das futuras gerações, criado pela UNESCO, o Instituto Internacional do Meio Ambiente (em inglês, International Environment Institute).

\footnotetext{
${ }^{7}$ Sobre o assunto: BROWN-WEISS, Edith. Justice pour les generations futures. Paris: UNESCO, 1993; ROJO SANZ, José Maria. Los derechos de las futuras generaciones. In: BALLESTEROS (ed.). Derechos humanos. Madrid: Tecnos, 1992; SIKORA; BARRY (eds.). Obligations to future generations. Philadelphia: Temple University Press, 1978. VISSER'T HOOFT, H. P. Développement technologique et responsabilité envers les générations futures. Archives de Philosophie de Droit, 1991, vol. 36, pp. 31-47.

${ }^{8}$ Na obra Teoría de la justicia. Madrid: FCE, 1979.

${ }^{9}$ Como se nota no livro POSSENTI. La società liberale al bivio. Genova: 1991.

${ }^{10} \mathrm{Em}$ seu texto HARDIN. Living in a Lifeboat. Bioscience, 24, 1974, p. 561 e ss.

ISSN 1981-3694

(C) 2008. Departamento de Direito da UFSM. Todos os direitos reservados.
} 


\section{b) $O$ conteúdo dos direitos}

Para o ecopersonalismo, os problemas ambientais fundamentais são aqueles relacionados com as condições de vida do ser humano, ou seja, com a saúde, a fome, a sede, e naquilo que lhe afeta, a desertificação e a perda da biodiversidade. Trata-se de proteger a integridade dos elementos físicos que possibilitam a vida, como a água, o ar e a terra e a conservação dos ecossistemas. Como se diz na Declaração internacional de experts em direito ambiental, incluída no relatório Bruntland: "Todos os seres humanos têm o direito fundamental a um meio ambiente adequado para sua saúde e bem-estar". A qualidade de vida engloba saúde e meio ambiente. Garantir as condições de vida dignas para todos, como já se previa na Constituição de Weimar e se repete na Declaração de Haia de 1989; eis o sentido do direito.

Resulta assim importante destacar o caráter substantivo do direito ao meio ambiente com relação a esse desenvolvimento saudável da personalidade de todos, que se depreende da carta do Rio de Janeiro, e de todos os textos constitucionais, em sentido contrário daqueles que apenas aceitam um direito procedimental ao meio ambiente ${ }^{11}$. O conteúdo essencial do direito ao ambiente seria dado pelo desenvolvimento duradouro no tempo e universal no espaço para todos, o que colocaria em primeiro lugar a dimensão da prevenção. Da mesma forma, é primordial a esse respeito a distinção entre satisfação de necessidades e simples desejos $^{12}$. O conteúdo essencial destaca a dimensão do homo aequalis ${ }^{13}$ e se opõe radicalmente ao homo xeconomicus, assim como ao individualismo conectado com a exigência básica do Estado social, que é a Daseinsvorsorge, a procura existencial. A defesa das condições dignas de vida para todos implica a consciência da interdependência mútua e a insuficiência do individuo isolado ${ }^{14}$.

Deve-se superar a concepção liberal que exalta a crematística e a acumulação como chave da organização social e recuperar a economia ecológica ou economia moral dos clássicos. É a mentalidade que tem sido designada como ecologismo dos pobres, ecologismo

\footnotetext{
${ }^{11}$ SERRANO, J. L. $2^{\text {a }}$ Semana de Derecho Ambiental. Universidad de Granada.

${ }^{12} \mathrm{Na}$ linha marcada por Georgescu-Roegen, interpretado por RICOLFI, Zamigni. Costituzioni, razionalità, ambiente. Turin: Bollati Boringheri, 1994, p. 254.

${ }^{13}$ GRASSI, ibidem, p. 415.

${ }^{14}$ RETORTILLO, Martín. El concepto de Daseinsvorsorge. Revista de Administración Pública, 1962, p. 42. ISSN 1981-3694

(C) 2008. Departamento de Direito da UFSM. Todos os direitos reservados.
} 
popular, ecologismo do $\mathrm{Sul}^{15}$, e que coincide como o que tenho denominado ecologismo personalista $^{16}$, tema que retomaremos mais adiante.

O conteúdo essencial do direito ao meio ambiente se conecta, com efeito, com a idéia de liberdades positivas, ou de participação, próprias da democracia clássica ou republicana ${ }^{17}$, as quais reaparecem na Constituição de Weimar e Bonn tendo por núcleo a noção de defesa de condições próprias da dignidade humana. Por isso, opõem-se às meras liberdades negativas, nas quais havia insistido o individualismo anglo-saxão, concentradas essas na defesa do direito ao isolamento e cuja chave é a liberdade como independência ${ }^{18}$.

Direito ao meio ambiente implica interdependência, liberdade positiva e democracia participativa, opondo-se à liberdade como independência, liberdade negativa e democracia como uma simples renovação das elites. Por isso que, como veremos depois, o direito à participação é uma das formas excelentes do direito ao meio ambiente e a mais indiscutível delas.

A fundamentação do direito ao meio ambiente não pode estar na teoria da vontade, mas na satisfação das necessidades ou interesses básicos, sempre que a defesa dos interesses se estenda aos necessitados de tutela, segundo afirma MacCormick ${ }^{19}$. Também deve dar-se uma democracia protetora, que defenda os direitos dos que carecem de voz, do mesmo modo que a tutela jurídica defende no âmbito privado os direitos dos menores.

Por isso, o direito ao meio ambiente se relaciona em primeiro lugar com o direito à saúde, às condições de salubridade dignas, tal como destaca o Relatório da OMS, Nosso Planeta, nossa saúde. A salubridade é o melhor indicador da degradação ambiental. Direito ao ambiente e direito à saúde se encontram unidos pela primazia do princípio da prevenção, da luta contra os riscos ou perigos que ameaçam a vida humana, o que, por sua vez, é encontrado no núcleo do Estado Social como o princípio da Daseinvorsorge, o que evidencia a importância que nele tem a temporalidade, como capacidade de antecipação e proteção contra o infortúnio. No direito a saúde se adverte a dependência dos direitos humanos no que diz respeito ao caráter corporal, mas a atenção à temporalidade fica limitada às gerações existentes; enquanto que, no direito ao meio ambiente, amplia-se a consciência da dependência ao conjunto da natureza e se estende a temporalidade ao futuro, de forma

\footnotetext{
${ }^{15}$ M. ALLIER. De la economía ecológica al ecologismo popular. Barcelona: Icaria, 1992.

${ }^{16}$ J. BALLESTEROS. Ecologismo personalista. Op. cit.

${ }^{17}$ Sobre o assunto: MACPHERSON. La democracia liberal y su época. Madrid: Alianza, 1981, p. 12 e ss., e OVEJERO. Op. cit.

${ }^{18}$ Sobre o assunto: GLENDON, M. A. Rights talk: the impoverishment of political discourse. Free Press, 1991.

${ }^{19}$ Como se pode notar no texto MacCORMICK. Los derechos de los niños. AFD, 1988, p. 293 e ss.
}

(C) 2008. Departamento de Direito da UFSM. Todos os direitos reservados. 
$\operatorname{ampla}^{20}$. Relaciona-se igualmente com o direito à alimentação, assim como com o direito à moradia, o que foi reafirmado em recente conferência de Istambul ${ }^{21}$.

\section{1) O destino universal dos recursos no espaço}

O imperativo categórico agora deve enunciar-se assim: "age de tal maneira que teu nível de consumo possa converter-se em máxima universal de conduta para ser compatível com condições de vida dignas para a presente e para as futuras gerações". A sobriedade ou frugalidade é a chave da atitude do ecologismo personalista ante os recursos, tal como já recolhia o Antigo Testamento com a instituição do Ano Sabático, que servia ao próprio tempo para fazer descansar a terra, evitando sua exploração em demasia, assim como fomentar a confiança em Deus e a sobriedade. Trata-se de uma concepção da propriedade antagônica à proposta no direito romano, que implicava o ius abutendi. Por isso, a terra não pode ser vendida para sempre, porque seu único e verdadeiro proprietário é Deus.

O homem é visto como pessoa, como relação solidária e interdependente com os outros. Será mais livre quanto maior o número de relações que tiver com os outros, e menor será sua dependência aos objetos; o que, como se verá, conduz à frugalidade anticonsumista $^{22}$.

Geralmente, reconhece-se que os direitos ambientais formam parte dos direitos de terceira geração, aqueles que devem explicar "as condições físicas e biológicas que tornaram possíveis" os direitos das gerações anteriores. Os direitos de liberdade religiosa ou pensamento da primeira geração afetam a realização plena da noção de pessoa; porém, a concepção a partir da qual foram formulados em seu aparecimento (o individualismo e o ideal cartesiano) impedia a cobrança da consciência de suas exigências sociais e ecológicas. Os direitos pareciam pertencer a indivíduos isolados e auto-suficientes.

Os direitos de segunda geração explicitam as exigências sociais dos direitos, destacando o direito a condições sociais dignas de vida (alimento, moradia, trabalho), sem os quais não são possíveis os direitos de primeira geração, ao contrário do que pretende Hayek,

\footnotetext{
${ }^{20}$ Sobre esse ponto têm insistido, com razão, os representantes do ecodesenvolvimento, especialmente: DUBOS, René. El espejismo de la salud. México, FCE, 1975; SACHS, Ignacy. Ecodesarollo. México: El Colégio de México, 1984.

${ }^{21}$ Sobre o assunto: KSENTINI. Informe sobre el derecho al medio ambiente. Consejo Económico y Social. Naciones Unidas, 1995, p. 94.

${ }^{22}$ Sobre o assunto: TAYLOR. Radici dell'io. Milão, Feltrinelli, 1993. Segundo lembra NASH (The rights of nature, 1989 apud OST. op. cit. p. 153, nota), o Secretário da Agricultura dos Estados Unidos pediu, já em 1936, uma "Declaração de Interdependência".
}

ISSN 1981-3694

(C) 2008. Departamento de Direito da UFSM. Todos os direitos reservados. 
ao basear-se em uma concepção de liberdade como algo carente de pressupostos. Desse modo, destacam a exigência dos outros, sendo direitos do ser humano em sociedade (= solidariedade sincrônica).

Os direitos de terceira geração, por sua vez, explicitam as condições de possibilidade dos direitos anteriores, desde o ponto de vista da física e da biologia. Sublinham o direito à sustentabilidade nas condições dignas de vida, como conseqüência dos pressupostos ecológicos; decorre daí a ênfase na temporalidade, nas futuras gerações (= solidariedade diacrônica).

É oportuno realizar uma distinção entre direitos de terceira geração e direito ao ambiente. Este pertence em sua dimensão mais específica aos direitos de terceira geração, ou direitos caracterizados pela exigência de duração. Porém, em sua dimensão procedimental, como direito de participação, é também um direito de primeira geração; e como dimensão substantiva, reporta-se ao direito à alimentação e à saúde, sendo, portanto, também um direito de segunda geração.

Os direitos ambientais como direitos de terceira geração, enquanto estabelecem um sentido de limite das ações humanas, em especial a frugalidade na utilização de recursos, podem eliminar as tensões entre os direitos da primeira geração (na medida em que reduzem a presença do Estado) e os da segunda (enquanto ampliam a referida presença). O elemento decisivo não seria agora o mercado ou o Estado, senão a responsabilidade pessoal e social. A solidariedade se opõe, portanto, à concepção voluntarista-liberal dos direitos, conduzindo a defender os direitos dos que não são atualmente autoconscientes e livres, como as futuras gerações. Contudo, o problema das gerações de direitos deve colocar-se em relação com o problema mais radical de sua interdependência recíproca, o que tem sido insistido nos documentos recentes das Nações Unidas e é estudado especialmente pelo suíço Meyer Abisch e, na Espanha, pela professora Encarnación Fernández.

A concepção de propriedade que torna possível o direito ao meio ambiente é, portanto, a concepção clássica que o concebe como poder de administração e distribuição, potestas procurandi et dispensandi. Somente esta permite atender o problema, quanto à sua conservação e cuidado, assim como no que tange à distribuição dos recursos da terra. Com efeito, Tomás de Aquino afirmava que o supérfluo é devido, segundo o direito natural, para o socorro dos pobres (Summa Theologiae, II-II, q. 66, a. 7), o que implica uma dupla solidariedade, sincrônica e diacrônica. 
Essa conservação e distribuição deveriam levar ao estabelecimento de sistemas de cotas para a eqüitativa utilização dos recursos naturais, como propõe Bermejo ${ }^{23}$. Isso se encontra com as antípodas do modo de pensar de Malthus, que primava completamente em favor do primeiro que utilizasse determinado recurso. Estas são suas terríveis palavras: "Um ser humano nascido num mundo que é já propriedade de outros, se a sociedade não necessitar do seu trabalho, não pode pretender o direito à menor porção de alimentos e de fato não tem nada o que fazer ali. No grande banquete da natureza não há para ele um lugar desocupado". A defesa de cotas de utilização dos recursos que as tornam possíveis para todos se enlaça com a crítica ao imperialismo demográfico, bem como com o conseguinte respeito à paternidade responsável, a qual se refere a Agenda 21, aprovado na Conferência Rio 92.

A problemática ambiental coloca sob suspeita, portanto, os conceitos de exclusividade e de livre disposição, substituindo-as pela de uma administração sustentável. Trata-se de evitar danos irreversíveis de caráter coletivo que poderiam supor destruição dos seres humanos e com isso de sua inalienabilidade, já que não existe o direito ao suicídio coletivo. Com isso, a natureza deixa de ser considerada como objeto ou sujeito para ser considerada como patrimônio, como instituição comum transtemporal e translocal ${ }^{24}$.

As notas economicistas de exclusividade e disponibilidade desaparecem quando o que se trata de defender é a vida ou os recursos naturais. O não-individualismo, por sua vez, conduz à exigência de recuperação da, assim chamada por Thompson, economia moral, cuja característica básica é a prioridade do direito à vida e a defesa dos bens comunais como algo que deve ficar fora do comércio, ou seja, fora do âmbito da crematística. Nessa primazia da economia moral se produz uma continuidade, que vai de Aristóteles a Georgescu-Roegen.

Este ecologismo dos pobres ou ecologismo igualitário se opõe ao socialdarwinismo ou ecologismo dos ricos, que remonta a Haeckel ${ }^{25}$. É o mesmo que a economia ecológica, a qual foi rechaçada por Marx ao assumir as categorias da economia política assim como a crença no caráter ilimitado dos recursos. A economia ecológica propugna a utilização comunitária dos recursos naturais e se opõe ao primado da crematística, ante as posturas neoliberais, como as de Garret Hardin, as quais enfatizam a necessária tragédia dos bens comuns.

\footnotetext{
${ }^{23}$ Em VV. AA. De la economía a la ecología. Madrid: Trotta, 1995, p. 63.

${ }^{24}$ OST. La nature. cit., p. 326 e ss.

${ }^{25}$ MARTÍNEZ ALLIER, Joan. Hacia una historia socio-ecológica: Algunos ejemplos andinos. In: SEVILLA GUZMÁN, E.; GONZÁLEZ DE MOLINA (ed.). Ecología, campesinado e historia. La Piqueta. Madrid, 1993. pp. 219-253.
}

ISSN 1981-3694

(C) 2008. Departamento de Direito da UFSM. Todos os direitos reservados. 
O conceito de economia moral, que vai de Aristóteles a Georgescu-Roegen, é reelaborado por Thompson $^{26}$, e, posteriormente, por Hobsbahm ${ }^{27}$. Sua base era o estabelecimento de condições de vida dignas para todos, assentada no fato de que Deus havia destinado todos os bens para todos os homens, o que implicava na inadmissibilidade do monopólio dos bens para determinados setores da população. Referido direito obrigava os poderes públicos a garantir a proteção especial dos desfavorecidos: viúvas, órfãos, anciãos. Ademais, justificava o protesto da multidão, quando da ausência de tais garantias. Por outro lado, a reciprocidade do direito a uma subvenção equivalente a um salário obrigava a evitar a ociosidade. A reciprocidade de direitos e deveres fazia com que essa economia fosse mais política, ante aquela que falsamente assim era denominada ${ }^{28}$. É certo que a economia moral era compatível com as hierarquias entre os seres humanos e o paternalismo. Apenas garantia a igualdade de condições mínimas; contudo, boa parte de suas idéias coincidia com o espírito do Common Law (p. 303) e, concretamente, com Blackstone, tendo, porém, em Burke o seu pior inimigo. Vale recordar que elas viriam a reaparecer com o socialismo ético de Owen, o que foi recuperado por Polanyi ${ }^{29}$. A dimensão fundamental era a existência de obrigações positivas em favor dos mais pobres. No prólogo de sua última obra, Costumes em comum, de 1991, afirma Thompson que a economia moral nos lembra as possibilidades da natureza humana e um modo de conceber as necessidades humanas, em que as satisfações materiais permanecem estáveis, enquanto que as necessidades culturais crescem, o que resulta especialmente interessante num momento em que o homo oconomicus, ao projetar suas satisfações apenas no âmbito material, pode estar a ponto de colocar em perigo a espécie humana através de um desastre ecológico (p. 27 e ss.). Isso leva a primar coerentemente os bens inclusivos sobre os exclusivos.

A visão cognitiva dos direitos humanos, própria da economia moral, coincide com a prioridade do direito à vida como direito fundante de todos os demais, começando pela saúde e pela alimentação, que reclama a subordinação do direito de propriedade. Por sua vez, desta primazia do direito à vida sobre o direito à propriedade se deduz a necessidade de limitar o livre comércio no caso dos alimentos, para não colocar em perigo a auto-suficiência alimentar, tal como reconhecem alguns liberais como o economista francês e Prêmio Nobel

\footnotetext{
${ }^{26}$ THOMPSON. Tradición, revuelta y consciencia de clase. Barcelona: Crítica, 1979.

${ }^{27}$ HOBSBAHM. El mundo del trabajo. Barcelona: Crítica, 1987, p. 302 e ss.

${ }^{28}$ THOMPSON. Costumbres en común. Barcelona: Crítica, 1995, p. 307.

${ }^{29}$ POLANYI. La gran transformación. Madrid: La Piqueta, 1994.
}

(C) 2008. Departamento de Direito da UFSM. Todos os direitos reservados. 
Maurice Allais ${ }^{30}$. O comércio mundial, ao que se refere o art. 12 da Declaração do Rio, deve ordenar-se de acordo com a prioridade da pessoa sobre os bens e, por conseguinte, deveria conduzir à liberdade de trânsito da população mundial e, na mesma medida, à proteção da agricultura e alimentos, reformando o GATT e a PAC. Há uma hierarquia de necessidades, que começa pelas atuais necessidades das pessoas em pior situação: o direito à alimentação é o primeiro direito, superior inclusive aos direitos das futuras gerações. É necessário acabar com o consumismo do Norte, que é completamente não-universalizável, porquanto estiver baseado num consumo em demasia e descontrolado. As necessidades de consumo endossomático de energia, ou alimento, podem variar relativamente pouco de uma pessoa para outra, mas os desejos de consumo de energia exossomática apresentam desigualdades de até 25 vezes. Essa divisão desigual de energia exossomática foi incrementada na passagem da civilização neolítica para a industrial, e desta para a nuclear ${ }^{31}$. Daí a urgência, por parte do direito ambiental, da luta pela introdução de energias alternativas, por exemplo, a energia solar, que nem destroem recursos não-renováveis, nem deixam resíduos ${ }^{32}$, e, ao mesmo tempo, de combater a desigualdade no acesso às suas fontes. Tal desigualdade choca frontalmente com o princípio de universalização, base do desenvolvimento sustentável, do que falaremos em seguida.

\section{2) O destino universal dos recursos no tempo. $O$ desenvolvimento sustentável}

Em razão de que os cientistas nem sempre chegam a um acordo quanto à interpretação dos processos ecológicos e, quando se certificam com unanimidade sobre sua existência, isso seria já com referência aos efeitos devastadores e irreversíveis, resulta essencial o princípio da precaução (sobre o assunto, Declaração do Rio). Esse princípio de precaução guarda íntima relação com o cuidado preventivo ou Vorsorge, o que, como destacou Forsthoff, é a base do Estado social de direito. Daí precisamente a compenetração entre os direitos ambientais e os deveres positivos dos Estados.

Neste principio de precaução, encontra-se a quebra do progressismo liberal, que crê que a História evolui necessariamente para melhor, assim como havia pensado boa parte dos

\footnotetext{
${ }^{30}$ OST. La nature hors la loi. cit., p. 227 e ss.; TOLEDO. Ecología y autosuficiencia alimentaria. México: Siglo XXI, 1985.

${ }^{31}$ Sobre o assunto: MUMFORD, L. Técnica y civilización. Madrid: Alianza, 1971.

32 Sobre o assunto: AEDENAT. Energía para el mañana: energía y equidad en un mundo sostenible. Madrid: Los libros de la catarata, 1993.
} 
autores do século XIX. Essa precaução pelo futuro é a chave da ética ecológica do cuidado, da qual se referia H. Jonas e é a razão pela qual se opõe o princípio de responsabilidade ao princípio esperança de Bloch, de sentido linearmente otimista. O princípio da precaução supera, por sua vez, o instantaneísmo, que limita a atenção ao instante presente.

Na Declaração de Estocolmo (Critério 1 e Princípio 10) se dá ênfase na qualidade de vida, identificada como o direito a condições de vida dignas ou vida saudável. Isso faz sinônimos direito à qualidade de vida e direito à saúde. Em ambos os casos, pressupõe-se o direito ao desenvolvimento (Critério 2), ou seja, à segurança alimentar, e o direito a não morrer por contaminação, em outros termos, à conservação do meio (Critério 1). Como direito-dever, a qualidade de vida supõe a superação do direito à vida entendido hobbesianamente como direito à pura segurança cidadã: direito a não sofrer atentados contra a vida ou a integridade física. Os direitos ao desenvolvimento e ao meio ambiente estão intimamente relacionados e requerem, por sua vez, a extensão do direito à vida até chegar à erradicação da guerra.

A vinculação entre o desenvolvimento e meio ambiente requer a planificação racional, termo referido nos princípios 13 a 15 de Estocolmo, mas que não reaparece nos princípios 3 e 4 da Carta do Rio. Nesse sentido, pode-se dizer que a passagem de Estocolmo a Rio é a passagem da planificação racional à sustentabilidade. No desaparecimento do conceito de planificação racional de Estocolmo resultou relevante a queda do socialismo real, o que levou a renunciar, talvez apressadamente, a busca de formas de planificação econômica não totalitária. De fato, a planificação reaparece no Tratado da União Européia através da ordenação territorial $^{33}$.

Para a ênfase do conceito de desenvolvimento sustentável foi decisivo o Relatório Bruntland (Nosso futuro comum). Esse Relatório das Nações Unidas de 1985, conhecido pelo nome de sua principal coordenadora, a primeira ministra noruega Gro Harlem Bruntland, define o desenvolvimento sustentável como "o desenvolvimento que satisfaz as necessidades da geração presente sem comprometer a capacidade das gerações futuras de satisfazer as suas". A sustentabilidade aparece como a linha de enlace entre desenvolvimento e meio ambiente e, portanto, entre seus correspondentes direitos. O relatório não declara suficientemente que o modelo de desenvolvimento do Norte é insustentável, e, portanto,

\footnotetext{
${ }^{33}$ M. MATEO. Ponencias. I Congreso de Derecho Ambiental Sevilla, Imprenta del Boletín Oficial del Estado, 1995, p. 18.
}

ISSN 1981-3694

(C) 2008. Departamento de Direito da UFSM. Todos os direitos reservados. 
imoral, ao incidir principalmente sobre a miséria do Sul como causa fundamental do desastre ecológico. Por isso, recebeu agudas críticas ${ }^{34}$.

A Declaração do Rio, no primeiro princípio, destaca, como dizíamos, que os "seres humanos constituem o centro das preocupações relacionadas com o desenvolvimento sustentável. Têm direito a uma vida saudável e produtiva em harmonia com a natureza". A noção de desenvolvimento sustentável aparece como o núcleo central de toda a Declaração da Terra do Rio de 1992. Aparece, com efeito, citado praticamente na totalidade de seus princípios. Qualquer projeto de desenvolvimento econômico aparece justificado em função da sua possibilidade de duração ou permanência a longo prazo, já que todos, presentes e futuras gerações, têm os mesmos direitos. A Carta do Rio parte principalmente dessa interdependência entre desenvolvimento e meio ambiente, implicando no conceito de desenvolvimento sustentável. Ele aparece agora como sinônimo de vida saudável, duradoura e de qualidade de vida estável para futuras gerações, recolhendo assim a ênfase na qualidade de vida, procedente de Estocolmo (I, 5). Desde tal efeito, o meio ambiente aparece como condição para o desenvolvimento (princípio 4).

O mais importante talvez seja que o conceito de desenvolvimento sustentável exige agora, claramente, a redução da produção e do consumo insustentáveis, em explícita crítica ao modelo de civilização tecnocrática. Mais concretamente, proclama que os países do Norte reconheçam "a responsabilidade que lhes corresponde na busca internacional de um desenvolvimento sustentável, em vista das pressões que suas sociedades exercem no meio ambiente mundial".

A conservação de recursos para futuras gerações exige a ecologização da economia, projetando a responsabilidade por longo prazo. O art. 7 da Carta do Rio destaca muito adequadamente a especial responsabilidade do consumismo do Norte, enquanto entra em contraste com o desenvolvimento sustentável. Assim, é evidente que o modelo de consumo dominante nos países do Norte, e muito especialmente nos Estados Unidos, possa ser considerado como insustentável porque não é extrapolável, uma vez que, como destaca o já citado relatório Bruntland, uns $20 \%$ da população consome a terceira parte dos recursos mundiais. Infelizmente, essas exigências não se plasmaram adequadamente em obrigações vinculantes para os Estados. Assim, o documento em que se tomam medidas mais concretas, sendo, por isso, o mais importante da Conferência do Rio, a Agenda 21, constitui a esse

\footnotetext{
${ }^{34}$ Confira entre outros: MARTÍNEZ ALLIER. Del ecologismo, apud MARTÍN SOSA. Ética ecológica. Madrid: Libertarias, 1990.
} 
respeito um diagnóstico certeiro da situação, mas resulta marcadamente insuficiente desde o ponto de vista do efetivo financiamento. Isso se deve, em grande parte, a que pelo visto só a Alemanha e a Holanda estavam dispostas a destinar 1\% de seu PIB, enquanto que os Estados Unidos não chegava a $0,7 \%$ e, sem comprometer-se com prazos, diziam que não necessariamente seria antes de 2000. Dessa forma, as nações pobres deveriam fazer frente a 80\% dos gastos (600 bilhões de dólares anuais).

\section{c) A dimensão procedimental do direito}

Os interesses difusos são uma peculiaridade do direito ao meio ambiente (semelhante aos interesses dos trabalhadores, que podem ser defendidos por sindicatos), que se produz enquanto os prejuízos ecológicos afetam a classe de pessoas (class action). Por essa razão:

a) A legitimação ativa em juízo pode ser exercida por alguém que atue como representante do grupo, como por exemplo, uma ONG. A diferença com os temas laborais é a maior amplitude do coletivo ou classe afetada: toda a sociedade enquanto afetada pelo risco ecológico.

b) A sentença tem efeitos para todos os prejudicados, estejam ou não pessoalmente ou representados em juízo. Isso se extrai da LOPJ (Ley Orgánica del Poder Judicial, da Espanha).

Os interesses difusos respondem ante a sociedade pelo risco que, segundo Beck, havia alcançado um determinado nível de igualdade de acordo com o princípio: "a fome é hierárquica, a contaminação atômica é igualitária”. Tal princípio igualitário se contradiz com a maior vulnerabilidade de determinados grupos, como destaca o relatório de Ksentini. Mais correta parece a idéia de Beck acerca da superação da noção de "assuntos internos", sobre os quais seria lícita a intervenção internacional ante ao perigo ecológico, que possui caráter de ir além das fronteiras ${ }^{35}$.

"Um grupo de ação ante os Tribunais pelos movimentos sociais não está baseado em um direito subjetivo no sentido clássico, ou seja, em um direito a defender uma porção de propriedade ou de interesse pessoal definido claramente, contra a intervenção do governo ou a interferência de algum partido privado. Os direitos de ação em favor da proteção de interesses difusos são direitos processuais que viabilizam que um foro social seja acessível aos

\footnotetext{
${ }^{35}$ Como se nota em La irresponsabilidad organizada. Debats, 1991, p. 31 e ss.
}

(C) 2008. Departamento de Direito da UFSM. Todos os direitos reservados. 
movimentos sociais" ${ }^{36}$. Tal como destacam, entre outros, Preuss, Beck, Unger ou Reich, os direitos ambientais questionam a categoria de direito subjetivo porque não são excludentes nem disponíveis, nem precisos, senão baseados em interesses difusos. A luta contra os direitos subjetivos que defendem interesses econômicos de conteúdo antiecológico é um processo semelhante ao da luta contra os privilégios na Idade Média ${ }^{37}$.

O aspecto procedimental do direito ao meio ambiente guarda uma grande relação com o direito à informação, tanto dos indivíduos frente ao Estado, como dos Estados frente as multinacionais. Exige a supressão do segredo por pretendidas razões de segurança nacional. Sua importância foi incrementada a partir de Chernobil e Bhopal, que são exemplos de desastres respectivamente provocados por empresas estatais e por multinacionais ${ }^{38}$.

O direito à informação possibilita o direito à educação ambiental, indispensável para a mudança de estilo de vida, indo do desperdício consumista à sobriedade e ao cuidado da natureza, bem como indo do instantaneísmo à cultura da duração, com o conseguinte repúdio à ecotecnocracia e ao desenvolvimentismo.

Um e outro desses direitos fazem possível, por sua vez, o direito à participação, o que, no âmbito da $\mathrm{CE}$, caminha intimamente ligado ao princípio da subsidiariedade, o qual foi elevado, a partir da declaração de Birmingham em 1992, à categoria de princípio geral ${ }^{39}$. Com isso, a participação é o Leitmotiv fundamental das Nações Unidas, junto à idéia de paz e desenvolvimento.

Em definitivo, o direito ao meio ambiente é inseparável da democracia participativa, na qual o desenvolvimento da personalidade de todos está acima dos interesses do mercado ${ }^{40}$. A democracia participativa surgiu precisamente da insatisfação das formas individualistas de democracia, por causa da sua incapacidade para atender aos problemas de qualidade de vida, e de eliminar os diferentes tipos de contaminação ${ }^{41}$.

\section{BIBLIOGRAFIA}

\footnotetext{
${ }^{36}$ REICH, em VVAA. Economía y Derecho. Madrid: Tecnos, 1992, p. 116.

37 Sobre a crítica ao conceito de direito subjetivo a partir da perspectiva ecológica, veja: BALLESTEROS. Postmodernidad: decadencia o resistencia. Madrid: Tecnos, 1989; SERRANO. Ecología y Derecho. Granada: Comares, 1992. BELLVER. Ecología: de las razones a los derechos. Granada: Comares, 1994.

${ }^{38}$ KSENTINI. Informe sobre el derecho al medio ambiente. Consejo Económico Social de Naciones Unidas, 1995.

${ }^{39}$ Sobre o assunto: MUÑOZ MACHADO. La Unión Europea y las transformaciones del Estado. Madrid: Alianza, 1993.

${ }^{40}$ MACPHERSON. La democracia y su época. Madrid: Alianza, 1981, p. 11.

${ }^{41}$ Ibidem. p. 124 e ss.
}

(C) 2008. Departamento de Direito da UFSM. Todos os direitos reservados. 
a) Mudança de paradigmas nos direitos: limitações do mercado

BALLESTEROS, Jesús. Ecologismo personalista. Madrid: Tecnos, 1995.

BELLVER, Vicente. Ecología: de las razones a los derechos. Granada: Comares, 1994.

BOURG, Dominique. Droits de l'homme et ecologie. In: VVAA. La nature en politique ou l'enjeu philosophique de l'ecologie. Paris: L'Harmattan, 1993.

LOMBARDI, Luigi (coord.). Il meritevole di tutela. Milano: Giuffrè, 1990.

MARTÍN MATEO, Ramón. Tratado de derecho ambiental. 2 v. Madrid: Trivium, 1992.

POSTIGLIONE, Amedeo. Il diritto all'ambiente. Napoli: Jovene, 1982.

SERRANO MORENO, José Luis. Ecología y derecho. Granada: Comares, 1992.

WOLFF, Raine. La protección ambiental, la paradoja de su justicia. Archives de Philosophie du Droit, 1991.

VVAA. Derecho y economía en el Estado social. Madrid: Tecnos, 1988.

b) Proteção internacional dos direitos: limitações à soberania

RIO 92. Textos y documentos. MOPT, 1992.

BARRERE, Martine (dir.). La tierra, patrimonio común. Barcelona: Paidós, 1992.

KISS, Alexandre. Los principios generales del derecho del medio ambiente. Universidad de Valladolid, 1975.

KISS, Alexandre. Droit international de l'environnement. Paris: Pedone, 1989. 
KISS, Alexandre (dir.). L'ecologie et le droit: le statut juridique de l'environnement. Paris, L'Harmattan, 1989.

SERRANO MORENO, José Luis. Ecología, Estado de Derecho y democracia. Anuario de Filosofía del Derecho, n. 10, 1993, pp. 151-174.

c) Deveres para com futuras gerações

BROWN-WEISS, Edith. Justice pour les générations futures. Paris: UNESCO, 1993.

ROJO SANZ, José María. Los derechos de las futuras generaciones. In: BALLESTEROS, Jesús (ed.). Derechos humanos. Madrid: Tecnos, 1992.

SIKORA, R. I.; BARRY, B. (eds.). Obligations to future generations. Philadelphia: Temple University Press, 1978.

VISSER'T HOOFT, H. P. Développement technologique et responsabilité envers les générations futures. Archives de Philosophie de Droit, 1991, vol. 36, pp. 31-47. 